\title{
Antityphoid Activity and Phytochemical Screening of Azadirachta Indica Leaf Extracts
}

\author{
Muhammad Alii ${ }^{*}$, Muhammad S. Abdallah ${ }^{2}$, Rabiu M. Kutama ${ }^{3}$ and Lurwanu Muazu ${ }^{4}$ \\ ${ }^{1}$ Department of Microbiology, Federal University Gusau, Nigeria \\ ${ }^{2}$ Desert Research Monitoring and Control Centre, Yobe State University Damaturu, Nigeria \\ ${ }^{3}$ Department of Biology, Saadatu Rimi College of Education, Nigeria \\ ${ }^{4}$ Department of Biological Sciences, Federal University Gusau
}

*Corresponding author: Muhammad Ali, Department of Microbiology, Federal

University Gusau, Nigeria, E-mail: alimuhd4real@gmail.com

Received Date: March 25, 2020

Published Date: April 03, 2020

\begin{abstract}
Herbal medicines have been known to human for centuries and practitioners of traditional medicine have described therapeutic efficacy of many indigenous plants for several disorders. The study was aimed to determine the anti-typhoid activity of Azadirachta indica leaf extracts against Salmonella typhi and Salmonella paratyphi isolated from typhoid fever patients. A clinical isolates of S.typhi and S. paratyphi were obtained from patients attending Murtala Muhammad Specialist Hospital, Kanowere tested against aqueous and methanol extracts of $A$. Indica leavesusing agar well diffusion method. The phytochemical screening of the extract was conducted using conventional laboratory methods. The result showed that the leaf extract of $A$. Indica contain alkaloids, tannin, anthraquinone, flavonoids, phenols and steroids. The result of antibacterial activity of the extracts against the test isolated indicated that the extracts were active against the isolate with higher activity shown by methanol extract (16.0 $\mathrm{mm}$ ) when compared to aqueous extract (13.5 mm). Salmonella typhi was found to be the most sensitive isolate (15.8 $\mathrm{mm})$ than S. paratyphi (13.3 $\mathrm{mm})$. It is concluded that the leaf extracts of $A$. indica were active against bacterial isolates associated with typhoid fever.
\end{abstract}

Keywords: Antibacterial activity, Azadirachta indica, phytochemicals, Salmonella typhi.

\section{Introduction}

Herbal medicines have been known to human for centuries. Practitioners of traditional medicine have described therapeutic efficacy of many indigenous plants for several disorders. This is due to the fact that plants contain many biologically active compounds which have potential for development as medicinal agents [1]. Herbal medicines already form the basis of therapeutic use in the developing countries, but of recent, there has been an increase in the use of herbal medicines in the developed world too [2]. It is likely that plants will continue to be a valuable source of new molecules which may, after possible chemical manipulation and provide new and improved drugs [3]. Bacterial resistance to antibiotics represents a serious problem for clinicians and the pharmaceutical industry and great efforts are being made to reverse this trend, and one of them is the widespread screening of medicinal plants from the traditional system of medicine hoping to get some newer, safer, and more effective agents that can be used to fight infectious diseases [4].

Enteric fever is a systemic bacterial infection caused by the Gram-negative Salmonella enterica serovar typhi (S. typhi) and the paratyphi serovars A, B and C (S. paratyphi A, B and C) of which S. paratyphi A is most common [5]. Enteric fever is a generic term for infections caused by both S. typhi and S. paratyphi. Typhoid and paratyphoid fever refers to the infections caused by the individual serovars [6]. Throughout this work enteric fever will be mostly used, but in cases focusing on $S$. typhi infections typhoid fever will also be used. S. typhi has historically been the most common cause of enteric fever but recently there have been several reports on the emergence of enteric fever caused by $S$. paratyphi A especially in Asia $[7,8]$.

Neem plants (Azadirachta indica) are mostly trees and rarely shrubs that belong to family Maliacea [9]. It is naturalized in most tropical and subtropical countries. It is broad-leaved evergreen that grows up to $30 \mathrm{~m}$ tall. The plant has been used for a long time in agriculture and medicine [4]. Neem is the most versatile, multifarious trees of tropics, with immense potential. All parts of the neem tree-leaves, flowers, seeds, fruits, roots and bark have been used traditionally for the treatment of inflammation, infections, fever, skin diseases and dental disorders [10]. The 
medicinal utilities have been described especially for neem leaf. Neem leaf and its constituents have been demonstrated to exhibit immunomodulatory, anti-inflammatory, anti-hyperglycaemic, antiulcer, antimalarial, antifungal, antibacterial, antiviral, antioxidant, antimutagenic and anticarcinogenic properties [11].

In 2012, the antimicrobial activity of leaf extract of neem was conducted against Pseudomonas aeruginosa, Staphylococcus aureus, Salmonella typhi and Bacillus pumillas and concluded that ethanol and methanol extract show maximum inhibition on Bacillus pumillas, Pseudomonas aeruginosa and Staphylococcus aureus in ascending order [12]. Neem leaf contains several valuable components such asisoprenoids that include terpenoids containing limonoids, azadirone and its derivatives [13]. The medicinal properties of the plant were studied by several workers, the antimalaria effect [14] antidiabetic effect [15] and anti-fertility effect [16], effect on the central nervous system[17], cardiovascular effect [18] and wound healing [19]. A indica has been shown to possess anti-microbial properties by several studies. Rao et al. [20] reported the antimicrobial activity of the seed oil against a variety of pathogens. Oils from the leaves, seeds and bark possess antibacterial action against certain bacteria [21]. Extracts of neem leaf, neem oil and seed kernels are effective against certain human fungi [11]. The study was aimed to determine the antityphoid activity of $A$. indica leaf extracts against S.typhi and S. paratyphi isolated from typhoid fever patients.

\section{Materials and Methods}

\section{Ethical approval}

Ethical approval (with reference no. HMB/GEN/492/VOL.1) for this research was obtained from the Hospital Service Management Board (HSMB), Kano based on the consent of Murtala Muhammad Specialist Hospital ethical committees

\section{Test isolates}

Two (2) bacterial strains of $S$. typhi and S. paratyphi isolated from typhoid fever patients were obtained from pathology laboratory of Murtala Muhammad Specialist Hospital, Kano. The isolateswere identified using different laboratory procedures including; Gram's stain, cultural characterization and Biochemical tests include (Indole, Methyl red, Voges Proskauer, and Citrate utilization) [22,23]. The isolates were maintained on Nutrient agar slants for further use.

\section{Collection of plant leaves and identification}

The leaves of A. indica were collected at Karfi village, Kura Local Government Area in Kano State, Nigeria. The identification and authentication of the plant materials was done at the Herbarium in the Department of Biological Science, Bayero University Kano with the following voucher number BUKHAN 0312, and voucher specimens were deposited there for future reference. The leaves were washed thoroughly with distilled water and shade dry for 2 weeks. The dry leaves were grinded into powder using a sterile pestle and mortar under laboratory condition. The powder was kept in air tight container for future use as described by Ali et al. [24].

\section{Preparation of plant extracts}

Methanol and water were used in the extraction process. Fifty grams (50 g) powder of the plant leaf was soaked in $500 \mathrm{~mL}$ each of distilled water and methanol respectively. The flasks were kept at room temperature for 3 days with intermittent shaking after which filtration was done using Whatman filter paper. The methanol extracts was evaporated at $50^{\circ} \mathrm{C}$ using rotary evaporator while the aqueous extract was evaporated at $40^{\circ} \mathrm{C}$ in water bath until dried extract samples were obtained. All the dried extract samples were dissolved in 10\% DMSO separately to the final concentration of 200 $\mathrm{mg} / \mathrm{mL}$ as a stock concentration. The stock solutions were stored in refrigerator at $4^{\circ} \mathrm{C}$ for further use [24].

\section{Qualitative phytochemical screening}

The qualitative phytochemical screening of the leaf extract of $A$. indica was conducted to determine the presence of various phytochemical components such as terpenoids, flavonoids, alkaloids, steroid, phenol, anthraquinone, saponin and tannin using standard methods as described by Sofowora [25] and Trease and Evans [26].

\section{Antibacterial activity of the extracts}

The antibacterial activity of the extracts against the isolates was determined using agar well diffusion method as described by Ali et al. [24] with slight modifications. The prepared bacterial suspension equivalent to $0.5 \mathrm{McF}$ arland Standard (equivalent to 1.5 x $10^{6} \mathrm{CFU}$ ) was inoculated into sterile Mueller- Hinton agar medium in a sterile Petri-dish. A sterile $6 \mathrm{~mm}$ diameter sterile cork-borer was used to bore 5 wells into the agar medium at equidistance. The wells were then filled up with approximately $0.1 \mathrm{~mL}$ of the extract solution at a concentration of 50,100, 150 and $200 \mathrm{mg} / \mathrm{L}$ taking care to prevent spillage onto the surface of the agar medium. The plates were allowed to stand on the laboratory bench for 1 hour to allow proper diffusion of the extract into the medium after which the plates were incubated at $37^{\circ} \mathrm{C}$ for 24 hours, and thereafter the plates were observed for zones of inhibition and measured. Amoxicillin $100 \mathrm{mg} / \mathrm{mL}$ (Pal Pharmacy) was used as a positive control in the experiment. The experiment was conducted in triplicate and the average zone of inhibition was calculated.

\section{Minimum inhibitory concentration (MIC)}

The minimum inhibitory concentration of the extract was determined using broth dilution technique. Two fold serial dilutions of the extracts were prepared by adding $2 \mathrm{~mL}$ of $200 \mathrm{mg} /$ $\mathrm{mL}$ of the extract into a test tube containing $2 \mathrm{~mL}$ of Nutrient broth, thus producing solution containing $100 \mathrm{mg} / \mathrm{mL}$ of the extract. The process continues serially up to test tube No. 5, hence producing the following concentrations; $100,50,25,12.5,6.25 \mathrm{mg} / \mathrm{mL}$. Test tube Number 6 does not contain extracts and serve as negative 
control. Exactly $0.5 \mathrm{~mL}$ of 0.5 McFarland equivalent standards of test organisms were introduced into the test tubes and incubated at $37^{\circ} \mathrm{C}$ for 24 hours. After incubation the test tubes were observed for growth by checking for turbidity [10].

\section{Minimum bactericidal concentration (MBC)}

Minimum Bactericidal Concentration of the extracts was determined using procedure of Ahmed and Beg [27].From each tube that did not show visible growth in the MIC, $0.1 \mathrm{~mL}$ was aseptically transferred into extract free Mueller Hilton agar plates. The plates were incubated at $37^{\circ} \mathrm{C}$ for 24 hours. The MBC was recorded as the lowest concentration of the extract that had less than $99 \%$ growth on the agar plates.

\section{Result}

\section{Phytochemical screening of the extracts}

The phytochemical constituents of aqueous and methanol leaf extracts of $A$. indica are presented in the table below Table 1. The result showed that both aqueous and methanol leaf extracts contain alkaloids, tannin, anthraquinone, flavonoids, phenols and steroids. Terpenoids are present in aqueous leaf extracts but absent in methanol extract. On the other hand, glycoside and saponin were absent.

Table 1: Phytochemical Screening of Aqueous and Methanol Leaf Extracts of $A$. indica.

\begin{tabular}{|c|c|c|c|}
\hline S/N & Phytochemicals & $\begin{array}{c}\text { Aqueous } \\
\text { extract }\end{array}$ & $\begin{array}{c}\text { Methanol } \\
\text { Extract }\end{array}$ \\
\hline 1 & Alkaloids & + & + \\
\hline 2 & Flavonoids & + & + \\
\hline 3 & Phenol & + & + \\
\hline 4 & Terpenoid & + & - \\
\hline 5 & Anthraquinone & + & + \\
\hline 6 & Glycosides & - & - \\
\hline 7 & Saponin & - & - \\
\hline 8 & Steroids & + & + \\
\hline 9 & Tannin & + & + \\
\hline
\end{tabular}

Key: + = Present, - = Absent.

\section{Antibacterial activity of the extracts}

The antibacterial activity of aqueous and methanol extracts of A. Indica against S. typhi and S. paratyphi is presented in Table 2. The result shows that highest antibacterial activity was demonstrated against $S$. Typhi with zone of inhibition of $21.70 \mathrm{~mm}$ at $200 \mathrm{mg} / \mathrm{mL}$ of methanol leaf extract. Zones of inhibition shown by control (100 $\mathrm{mg} / \mathrm{mL}$ Ciprofloxacin) were $25.30 \mathrm{~mm}$ and $23.70 \mathrm{~mm}$ for $S$. typhi and S. paratyphi respectively.

\section{MIC and MBC of the extracts}

Minimum inhibitory concentration (MIC) and minimum bactericidal concentration (MBC) of aqueous and methanol extracts of $A$. indica against $S$. typhi and $S$. paratyphi is presented in presented in Table 3. The result shows that dilutions of various concentrations of the plant leaf extract are active against test isolates. The MIC ranges from $6.25-25 \mathrm{mg} / \mathrm{mL}$ while MBC ranges from $12.5-50 \mathrm{mg} / \mathrm{mL}$.

Table 2: Antibacterial Activity of the Extracts against S. typhi and S. paratyphi.

\begin{tabular}{|c|c|c|c|}
\hline Extract & $\begin{array}{c}\text { Concentration } \\
(\mathrm{mg} / \mathrm{mL})\end{array}$ & S. typhi & S. paratyphi \\
\hline \multirow{4}{*}{$\begin{array}{c}\text { Aqueous leaf } \\
\text { extract }\end{array}$} & 50 & $10.30 \pm 0.12$ & $9.70 \pm 0.17$ \\
\hline & 100 & $12.30 \pm 0.07$ & $10.30 \pm 0.20$ \\
\hline & 150 & $15.70 \pm 0.09$ & $13.30 \pm 0.09$ \\
\hline & 200 & $19.70 \pm 0.10$ & $15.70 \pm 0.06$ \\
\hline \multirow{2}{*}{ Control } & & $25.3 \pm 0.20$ & $23.7 \pm 0.14$ \\
\hline & 50 & $12.30 \pm 0.21$ & $10.70 \pm 0.10$ \\
\hline \multirow{3}{*}{$\begin{array}{l}\text { Methanol leaf } \\
\text { extract }\end{array}$} & 100 & $16.70 \pm 0.16$ & $15.30 \pm 0.07$ \\
\hline & 150 & $17.30 \pm 0.07$ & $15.70 \pm 0.12$ \\
\hline & 200 & $21.70 \pm 0.09$ & $18.30 \pm 0.08$ \\
\hline
\end{tabular}

Table 3: MIC and MBC of the Extracts.

\begin{tabular}{|c|c|c|}
\hline Extracts & S. typhi & S. paratyphi \\
\hline Aqueous Leaf Extract & $12.5 / 50$ & $25 / 50$ \\
\hline Methanol Leaf Extract & $12.5 / 12.5$ & $12.5 / 25$ \\
\hline
\end{tabular}

\section{Discussion}

The presence of secondary metabolites in plant lead to production of some biological activity of the plant in man and it is responsible for their use as herbs [10]. These compounds also serve to protect the plant against infection by microorganisms, predation by insects and herbivores, while some give plants their odors and /or flavors and some still are responsible for their pigments [2]. Salmonellosis and enteric fever are always a public health concern in most developing countries, which are mostly low or middle-income countries with inadequate sanitation and hygiene, particularly regarding food, water and disposal of human excreta [28].

The result of the present study revealed the present of phytochemical compound in the leaf extracts of $A$. indica. This result was in conformity with the result of several findings conducted by many researchers [29]. A. indica leaf contains several valuable components such as alkaloid, flavonoid and isoprenoids that include terpenoids containing limonoids, azadirone and its derivatives [13].Many plants have been investigated scientifically for antimicrobial activity and a large number of plant products have been shown to inhibit growth of pathogenic bacteria [30]. Some of these metabolites particularly the flavonoids, tannin and alkaloid were reported to be responsible for antimicrobial activity associated with some ethno-medicinal plant [31].

The antibacterial property of the extracts against the test isolates revealed that $S$. Typhi showed the highest zones of inhibition $(23 \mathrm{~mm})$ than $S$. paratyphi. This result justifies the finding of Al-Akel et al. [28]. The leaf extracts of the plant is known 
to possess antibacterial activity against pathogenic bacteria such as Pseudomonas aeruginosa, Staphylococcus aureus, Salmonella typhi and Bacillus pumillas [12]. The antimicrobial activity of the leaf extracts is attributed to the presence of phytochemical constituents in the plant's leaves. The methanol extract was found more active than aqueous extract and this justified several studies conducted involving aqueous and organic extract [10,24,32] since most studies have reported that organic solvents were better chemical reagents for consistent extraction of antimicrobial substances from medicinal plants. The test organisms had the same minimum inhibitory concentration (MIC) value ranges of 6.25 to $25 \mathrm{mg} / \mathrm{mL}$ and minimum bactericidal concentration (MBC) value ranges of 12.5 to $50 \mathrm{mg} / \mathrm{mL}$. This indicated that the leaves A. indica possessed antibacterial property against $S$. typhi and $S$. paratyphi. This is similar to the findings of the National Library of Medicine at the National Institutes of Health (www.pubmed.com) who reported that in test tubes, A. indica has been shown to have significant effects on both Gram-positive and Gram-negative organisms and other bacteria that cause a wide array of human and animal diseases.

\section{Conclusion}

It may be concluded from this study that $A$. indica leaf extracts have antibacterial activity against $S$. typhi and S. paratyphi isolated from typhoid fever patients. The antibacterial activity is probably due to the presence of phytochemical constituents such as alkaloids, tannin, anthraquinone, flavonoids, phenols and steroids. The wide use of $A$. indica is attributable to the presence of these bioactive compounds, which may explain its many traditional uses against typhoid fever.

\section{Acknowledgement}

The authors wish to acknowledge the technical staff of Pathology Department of Murtala Muhammad Specialist Hospital for samples provision. Thanks to Kano State Government through Ministry of Health for the ethical approval.

\section{Conflict of Interest}

No Conflict of Interest.

\section{References}

1. De N, Ifeoma E (2002) Antimicrobial effects of components of the bark extracts of neem (Azadirachta indica A. Juss). J. Technol. Dev 8: 2328.

2. El-Mahmood AM, Ogbonna OB, Raji M (2010) The antibacterial activity of Azadarichta indica (neem) seed extracts against bacterial pathogens associated with eye and ear infections, Journal of Medicinal Plants Research 4(14): 1414-1421.

3. Shah JS, Shah MB, Goswami SS, Santani DD (2006) Mechanism of action of antiulcer activity of bark extracts of Manikarahex andra against experimentally induced gastric ulcers in rats. Phcog. Mag 2: 40-45.

4. Natarajan V, Veugopal PV, Menon T (2003) Effect of Azadirachta indica (neem) on the growth pattern of Dermatophytes, Indian J Med Microbiol 21(2): 98-101.

5. Bhan MK, Bahl R, Bhatnagar S (2005) Typhoid and paratyphoid fever. The Lancet 366(9487): 749-762.

6. Woods CW, Murdoch DR, Zimmerman MD, Glover WA, Basnyat B, et al. (2006) Emergence of Salmonella enterica serotype paratyphi A as a major cause of enteric fever in Kathmandu, Nepal. Trans. R. Soc. Trop. Med. Hyg 100(11): 1063-1067.

7. Ochiai RL, Wang X, von Seidlein L, Yang J, Bhutta ZA, et al. (2005) Salmonella paratyphi A Rates, Asia. Emerg. Infect. Dis 11(11), 17641766.

8. Sahastrabuddhe S, Carbis R, Wierzba TF, Ochiai RL (2013) Increasing rates of Salmonella paratyphi A and the current status of its vaccine development. Expert Rev. Vaccines 12(9): 1021-1031.

9. Margaret SN (1965) Introduction to the flowering plants of West Africa. (2nd edition).University of London Press Limited, London 169.

10. Nas FS, Ali M (2017) Phytochemical screening and Antibacterial Activity of Azadirachta indica Stem and Leaf Extracts on Escherichia coli and Staphylococcus aureus Isolated from Spoiled Cabbage. Journal of Pharmaceutical and Allied Sciences 14(4): 2616-2624.

11. Biswas K, Chattopadhyay I, Ranajit KB, Bandyopadhya U (2002) Biological activities and medical properties of neem (Azadirachta indica). Current Sciences 82 (11): $1336-1345$.

12. Brindha MS, Kariyarasi S, Annadurai NS, Gangwar SK (2012) Antimicrobial activity in leaf extractof Neem (Azadirachta indica ). International journal of science and Natural 3: 110.

13. Xu J, Du YH, Yin ZQ, Li XT, Jia RY, et al. (2010) The preparation of neem oil microemulsion (Azadirachta indica) and the comparison acaricidal time between neem oil microemulsion and other formulation in vitro. Veterinary Parasitology 169(3-4): 399-403.

14. Rochankij S, Thebraranonth Y, Yenjal C (1985) Nimbolide a constituent of A. indica inhibits Plasmodium falciparum in culture. South East Asian Journal Tropical Medicine and Public Health 16(1): 66-72.

15. Shukla R, Singh S, Bhandari CR (1973) Preliminary clinical trail on antidiabetic actions of Azadirachta indica. Medicine and Surgery 13: 1112 .

16. Sinha KC, Riar SS, Tiwarry RS, Dhawan AK, Bhadhan J, et al. (1984) Neem oil as a vaginal contraceptive. Indian Journal of medicinal Research 79: 131-136.

17. Phillai NR, Shanthakumari G (1984) Effect of nimbidin as acute and chronic grastroduodenal ulcer models in experimental animals. Planta Medica 50(2): 143-146.

18. Thompson EB, Anderson CC (1978) Cardio vascular effects of Azadirachta indica extract. Journal of Pharmaceutical Sciences 67(10): 1476-1478.

19. Jayaprakasan MV, Viswanathan K, Rajesh M, Pradymnan PP (2014) Ayurvedic preparation from Azadirachta indica, Terminaliachebula, Hemigraphiscolorataextracts and its antimicrobial investigation, IOSR Journal of Pharmacy and Biological Sciences 9(2): 01-06.

20. Rao DVK, Sing K, Chopra R, Chatra PC, Ramanujalu G (1986) In vitro antibactericidal activity of neem oil. Indian Journal of Medicinal Research 84: 314 -316.

21. Khan M, Wassilar SW (1987) In natural pesticides from the Neem tree and other Tropical plants. Schmutterer H, Asher KRS Eds. Eschborn, Germany, pp. 650.

22. Holt JG, Krieg NR, Sneath PA, Stanley JT, Williams ST (1994) Bergey's manual of systematic bacteriology. Williams (Edt.), $\left(9^{\text {th }}\right.$ edn), Baltimore, Maryland, USA, pp.786.

23. Cheesbrough M (2006) District Laboratory Practice in Tropical Countries, $\left(2^{\text {nd }}\right.$ edn), Part Two, Cambridge University Press, USA, pp. 8085 .

24. Ali M, Yahaya A, Zage AU, Yusuf ZM (2017) In vitro Antibacterial Activity and Phytochemical Screening of Psidium guajava on Some Enteric Bacterial Isolates of Public Health Importance. Journal of Advances in Medical and Pharmaceutical Sciences 12(3): 1-7.

25. Sofowora A (1993) Medicinal Plants and Traditional Medicine in Africa. John Wiley and Sons Ltd. New York, London, pp. 143-145 
26. Trease GE, Evans WC (1983) Pharmacognosy. (12 ${ }^{\text {th }}$ edn), English Language Book Society, Bailliere Tindall, pp. 374-404.

27. Ahmed I, Beg AZ (2001) Antimicrobial and phytochemical studies on 45 Indian Medicinal plants against multi-drug resistance human pathogens. J Ethnopharmacol 74(2): 113-123.

28. Al Akeel R, Ayesha Mateen A, Janardhan K, Gupta VC (2017) Analysis of anti-bacterial and anti-oxidative activity of Azadirachta indica bark using various solvents extracts. Saudi Journal of Biological Sciences 24(1): 11-14.

29. Timothy SY, Adamu S, Nyandaiti WY, Sugun MY, Bukbuk DN (2011) Phytochemical and Antimicrobial Activity of Aqueous leaf extract of
Sennasiamea(Lam.) on Enterobacteriaceae. Nig J. of Exp. and Applied Biol 9(2): 159-163.

30. Naima S, Muhammad RK, Maria S (2012) Antioxidant activity, total phenolic and total flavonoid contents of whole plant extracts Torilisleptophylla L. BMC Complement. Altern. Med 12: 221.

31. Atto V, Koffi DP, Monteomo GF, Adeoti MF (2016) Phytochemical Screening of Sclerocarya birrea (Anacardiaceae) and Khaya senegalensis (Meliaceae), antidiabetic plants. Int J Pharm Chem 2(1): 1-5.

32. Sasidharan S, Chen Y, Saravanan D, Sundram KM, Latha LY (2011) Extraction, isolation and characterization of bioactive compounds from plants extracts. Afr J Tradit Complement Altern Med 8(1): 1-10. 